\title{
Urodimento
}

REVISTA DE ESTUDOS EM ARTES CÊNICAS

E-ISSN 2358.6958

\section{Processos criativos remotos em teatro: Um diálogo entre a Análise Ativa de Stanislavski e o RPG}

\author{
Martha Dias da Cruz Leite \\ Vitor Hugo Moreira Lima Compadre
}

Para citar este artigo:

LEITE, Martha Dias da Cruz; COMPADRE, Vitor Hugo Moreira Lima. Processos criativos remotos em teatro: Um diálogo entre a Análise Ativa de Stanislavski e o RPG. Urdimento - Revista de Estudos em Artes Cênicas, Florianópolis, v. 2, n. 41, set. 2021.

doi DOI: http:/dx.doi.org/10.5965/1414573102412021e0119

Este artigo passou pelo Plagiarism Detection Software | iThenticate 
Processos criativos remotos em teatro: Um diálogo entre a Análise Ativa de Stanislavski e o RPG

Martha Dias da Cruz Leite ${ }^{1}$

Vitor Hugo Moreira Lima Compadre ${ }^{2}$

\begin{abstract}
Resumo
O texto apresenta os resultados de pesquisa que investigou procedimentos metodológicos para criação de uma peça de teatro virtual, a partir do diálogo entre a Análise Ativa de Stanislavski e elementos do RPG. Discute conceitos teóricos, descreve os caminhos metodológicos adotados e, por fim, tece uma reflexão sobre o processo de criação cênica em formato remoto. A reflexão busca evidenciar que, ainda que experiência do teatro virtual não possa ser simetrizada ao teatro presencial, o teatro virtual possui potência para ser mais do que uma alternativa emergencial de produção cênica em contexto pandêmico, agregando possibilidades formais dentro do grande rol de experiências que se entende por teatro contemporâneo.
\end{abstract}

Palavras-chave: Análise Ativa. Stanislavski. RPG. Teatro virtual.

\title{
Remote creative processes in the theater: Stanislavski's Active Analysis and RPG
}

\begin{abstract}
This paper investigates methodological procedures used to create a virtual theater play, based on Stanislavski's active analysis and elements of RPG (role playing games). It discusses theoretical concepts, describes methodological choices, and, in conclusion, reflects upon the creative process in a remote context. This reflection intends to emphasize that, even though the experience of virtual theater does not equate with live theater, virtual theater has the potential to be more than a remedial production alternative in the context of a pandemic, aggregating formal possibilities within the great array of experiences that we understand as contemporary theater.
\end{abstract}

Keywords: Active Analysis. Stanislavski. RPG. Virtual theater.

${ }^{1}$ Doutoranda em Educação pela Faculdade de Educação da Universidade de São Paulo (USP). Mestrado pelo Programa de Pós-Graduação em Artes pela Universidade Estadual de Campinas (UNICAMP). Bacharelado em Artes Cênicas Campinas (UNICAMP). Professora efetiva do curso de Graduação em Artes Cênicas Licenciatura em Teatro da Universidade Estadual de Maringá (UEM). mdcleite@uem.br

(9) http://lattes.cnpq.br/9624869144891229 $\quad$ (iD https://orcid.org/0000-0003-0144-3228

2 Graduação em Artes Cênicas - Licenciatura em Teatro pela Universidade Estadual de Maringá (UEM). vitorvaldis@gmail.com

(9) http://lattes.cnpq.br/0421384539656617

(iD) https://orcid.org/0000-0002-1576-1991 
Procesos creativos remotos en teatro: un dialogo entre la Análisis Activa de Stanislavski y el RPG

\section{Resumen}

El texto presenta los resultados de la pesquisa que investigó procedimientos metodológicos para la creación de una pieza de teatro virtual, a partir del dialogo entre el Análisis Activa de Stanislavski y los elementos del RPG. Discute conceptos teóricos, describe los caminos metodológicos adoptados y, por fin, teje una reflexión acerca del proceso de creación escénica en formato remoto. La reflexión busca evidenciar que, aunque la experiencia del teatro virtual no se puede ser simetrizada al teatro presencial, el teatro virtual tiene potencia para ser más que una alternativa de emergencia de la producción escénica en un contexto pandémico, agregando posibilidades formales dentro de la gran lista de experiencias que se entiende como teatro contemporáneo.

Palabras-clave: Análisis Activa. Stanislavski. RPG. Teatro virtual. 
Durante o período pandêmico destacou-se a proliferação de criações e produções teatrais feitas de maneira remota, ou o chamado teatro virtual, devido às necessidades impostas pelo distanciamento social. Na esteira de tais iniciativas, crescem também os questionamentos acerca da validade desse tipo de empreendimento quanto a sua condição de teatro. Afinal, o teatro virtual pode ser entendido como teatro? Entre olhares desconfiados que não concebem a presença virtual como teatro e vozes que proclamam que o "virtual é potência" (Pessoa, 2020, s/p.), o fato é que a polêmica se instaura com força mediante a necessidade de artistas continuarem ativos em suas produções à revelia do isolamento social. Contudo, apesar do caráter quase impositivo que a virtualidade adquire nesse contexto, tais iniciativas não poderiam se revelar como potentes experimentações artísticas em si? Para além de conceber o teatro virtual como uma mera "saída de emergência" em tempos pandêmicos, mas sem cair em um ufanismo intempestivo que condena o teatro presencial como "coisa do passado", o presente artigo argumenta em prol de uma ideia de teatro virtual não simetrizada à experiência do teatro presencial, seja pelo crivo da substituição ou da superação, e sim, como apenas mais uma possibilidade poética dentro do grande rol de experiências que se entende por teatro contemporâneo. Para isso, apresenta uma reflexão com base no percurso criativo do espetáculo virtual Complexo de Oféliả, expondo os caminhos metodológicos encontrados pelos artistas envolvidos para com as demandas específicas da criação em ambiente virtual e da realização de ensaios em formato remoto.

A dramaturgia de Complexo de Ofélia teve como inspiração as trajetórias de quatro personagens shakespearianas: Ofélia; Lady Macbeth, Helena e Julieta. O texto inicial foi concebido para ser reconstruído por meio de improvisações, como procedimento integrante de uma experimentação criativa que objetivou investigar um diálogo entre a Análise Ativa de Stanislavski e o Role-Playing Game (RPG), gênero de jogo no qual os jogadores assumem o papel de personagens e criam

O espetáculo Complexo de Ofélia é resultante de pesquisa de iniciação científica realizada na Universidade Estadual de Maringá, no curso de Artes Cênicas - Licenciatura em teatro. O discente-pesquisador Vitor Hugo Moreira Lima Compadre assumiu no processo de criação as funções de diretor, dramaturgo e mestrenarrador. Os ensaios foram realizados de forma integralmente remota, e o espetáculo ocorreu em ambiente virtual. 
narrativas orais improvisadas, a partir de um sistema de regras predeterminado. Como norteador para a escrita, utilizou-se o artigo de Marcia Tiburi Ofélia morta: do discurso à imagem (2010), no qual a autora apresenta o conceito de Complexo de Ofélia: a necessidade das tragédias de apresentarem a morte de uma ninfa. A estreia da peça Complexo de Ofélia, ou seja, sua disponibilização na internet na plataforma YouTube, foi realizada no dia 27 jan. 2021 às 20 horas, onde segue disponível para visualização ${ }^{4}$.

A seguir, uma explanação das bases teórico-metodológicas que guiaram as investigações criativas de Complexo de Ofélia.

\section{Análise Ativa de Stanislavski: princípios norteadores básicos}

Compreender as propostas e pesquisas de Stanislavski - o chamado Sistema stanislavskiano de interpretação - passam por algumas dificuldades de largada, dado o impacto de circunstâncias comerciais, políticas e sociais que nutrem mitos e distorções acerca de seu trabalho: escritos que frequentemente se tornam versões modificadas com visões parciais (ou até mesmo distorcidas) de suas ideias, devido, entre outros fatores, à pressões por parte das editoras em prol de livros mais comerciáveis; e até mesmo a censura e eliminação de textos que iam de encontro às normas do partido oficial da União Soviética (Carnicke; Carvalho, 2021). Desta forma, para explanar aspectos importantes do que se consolidou denominar no ocidente como Análise Ativa, é importante fazer uma recapitulação histórica, que tem início no Estúdio de Ópera e Arte Dramática, também conhecido como o último estúdio de Stanislavski, que existiu de 1935 a 1938. Esse estúdio, de acordo com Diego Fernandes Garcia Moschkovich (2019b, p. 235), "estabeleceria as bases pedagógicas para a continuidade das pesquisas iniciadas com a fundação do Teatro de Arte de Moscou, em 1898".

Stanislavski desde o começo dos anos 1920 tinha o desejo de sistematizar uma pedagogia própria, chegando até mesmo a pedir no ano de sua morte que Z.S. Sokolova, sua irmã, escrevesse um manual pedagógico do seu Sistema (KS

${ }^{4}$ Link para o espetáculo: https://www.youtube.com/watch?v=NPJS4FQAvNE 
$16907^{5}$ apud Moschkovich, 2019b). Alguns dos termos mais utilizados no ocidente para referir-se ao legado de Stanislavski são o Método das Ações Físicas e o Método da Análise Ativa; contudo, nem um nem outro são expressões criadas e atribuídas por Stanislavski para a sua própria pesquisa pedagógica, e se tratam, em última instância, de leituras específicas do seu trabalho feita por alguns discípulos, mais especificamente Mikail Kédrov e Maria Knebel (Moschkovich, 2019b).

Após a morte de Stanislavski, em 1938, Mikhail Kédrov assume a direção do Estúdio de Ópera e Arte Dramática, e foi Kédrov o criador da denominação Método das Ações Físicas, expressão oficialmente aceita na tradição como a síntese dos experimentos conduzidos por Stanislavski. Já a expressão Análise Ativa, ou análise através da ação (neste trabalho não entraremos na complexa e extensa polêmica que envolve o problema das traduções quando se trata da obra de Stanislavski), seria conhecida um pouco mais tarde, por meio de Knebel, somente depois que o Teatro de Arte de Moscou (TAM) caísse em uma crise criadora sem precedentes nas mãos Kédrov, nos anos 1950.

Kédrov, provavelmente predisposto a dar uma coesão aos experimentos de Stanislavski (para não dizer - transformá-lo num "método" que trouxesse resultados!), introduz algumas mudanças significativas na pedagogia do estúdio, transformando-o, de fato, menos em um estúdio experimental e mais num teatro de repertório (Moschkovich, 2019a, p.90).

Dessa forma, pode-se dizer que a recepção do sistema de Stanislavski no ocidente consiste, na verdade, na recepção de diferentes métodos trabalhados no último estúdio, sobretudo após a morte de Stanislavski, e se diferenciam entre si de acordo com o encaminhamento dado pelos variados discípulos e herdeiros de seu legado. De uma forma geral, a prática ocidental se dá fortemente influenciada pela leitura que Jerzy Grotowski faz do Livro de memórias Stanislavski Ensaia, de Vassíli Toporkov. Já no Brasil, as duas vias de acesso direto mais importantes ao trabalho de Stanislavski foram: Eugênio Kusnet, diretor e pedagogo brasileiro que na década de 1960 estuda com Maria Knebel na URSS, e traz para o Brasil, por meio da escrita do livro Ator e Método (1985), as suas impressões a respeito da

${ }^{5}$ Fundo Stanislavski (KS), documento número 16907. 
metodologia da Análise Ativa; e Nair D’Agostini, professora de teatro que estudou na URSS com Gueórgui Tovstonógov na década de 1980, fundando um curso de teatro na Universidade Federal de Santa Maria (RS), que consolidou-se como um dos primeiros laboratórios de pesquisa e experimentação no país acerca do trabalho desenvolvido no último estúdio (Moschkovich, 2019b).

Para Knebel, são três os fatores que levaram Stanislavski a criar uma forma de trabalho e pedagogia para o ator: a passividade do ator no processo criativo durante os ensaios, a separação do aspecto físico e psíquico do ator e, por fim, a importância da fala do ator. Essas seriam as principais premissas da criação do que foi consagrado como Análise Ativa, ou simplesmente método da análise através da ação. Nesse método, o ator não iniciaria a criação decorando suas falas, mas sim, emergindo em um processo de recriação da ação da peça através de suas próprias palavras e ações físicas, por meio de procedimentos previamente elaborados (Fritsch, 2015).

A discípula do diretor russo reafirma a luta que Stanislavski teria travado contra a passividade do ator: ao buscar, em todos os momentos do processo criativo, oportunidades para que o intérprete fosse ativo, Stanislavski almejaria tornar a contribuição do ator equiparável ao trabalho do diretor e do dramaturgo (Fritsch, 2015). Outro ponto de preocupação para Stanislavski seria a dissociação dos aspectos físicos e psíquicos, que poderiam ocorrer durante o chamado trabalho de mesa, ao colocar o ator em uma posição de passar muito tempo debatendo teoricamente sobre a personagem sem experimentar em seu corpo uma prática interpretativa. A Análise Ativa ofertaria uma solução possível ao impasse, colocando o ator em cena antes mesmo dele decorar o texto, de forma que ele já pudesse trabalhar a linha das ações físicas da personagem e a situação dramática da peça. E, por fim, o que é considerada por Knebel a mais importante premissa na criação do método da análise através da ação: a questão da fala. O diálogo ocuparia um lugar fundamental na atuação, logo, o costume de decorar o texto mecanicamente deveria ser abolido, para que a fala surgisse aparentando naturalidade. Sendo assim, seria primordial que os atores usassem suas próprias palavras no processo de criação da personagem para expressar as ideias contidas no texto original, dando mais dinamismo e verossimilhança à cena. 
Stanislávski concluiu que o ator pode chegar à palavra viva somente como resultado de um intenso trabalho preparatório, que o leve a necessitar das palavras do autor como algo imprescindível para expressar as suas ideias. Qualquer memorização mecânica do texto leva ao fato de que o ator, nas palavras de Stanislávski, 'senta-se sobre os músculos da língua', ou seja, converte seu trabalho em clichês, em algo morto. No início do trabalho, segundo a ideia de Stanislávski, os atores precisam das palavras escritas pelo autor não para serem decoradas, mas para descobrir nelas as ideias depositadas pelo autor (Knebel ${ }^{6}$, 1959, p.8, apud Fritsch, 2015, p.108).

Ao trabalhar no desenvolvimento de uma proposta pedagógica para o ator em cima das premissas deixadas pelo diretor russo, Maria Knebel tenta dar continuidade ao trabalho de Stanislavski após a sua morte. Com a análise através da ação, o ator poderia ter em sua mente uma espécie de mapa que o possibilitaria improvisar e agir de acordo com as circunstâncias dramatúrgicas propostas, sem precisar estar com um texto decorado, diferindo, portanto, da livre improvisação, já que a Análise Ativa se desenvolve necessariamente em cima de uma estrutura (Fritsch, 2015).

Eugênio Kusnet aborda a Análise Ativa como um método em que o ator utiliza a improvisação para analisar o material dramatúrgico em ação, em contraste com o tradicional trabalho de mesa, procurando "compreender a obra dramática através da ação praticada pelos intérpretes dos papéis na base de conhecimentos superficiais da peça” (Kusnet, 1985, p.98). Em seu livro Ator e Método (1985), elenca os passos necessários para o que, na sua visão, seria a consolidação prática da Análise Ativa. Aponta que é possível realizar na maioria dos textos dramáticos uma divisão em partes menores, objetivando um melhor estudo sobre cada cena, como se colocássemos uma lente de aumento sobre o corpo do texto para ver melhor os detalhes. Para tanto, seria preciso, primeiramente, localizar cenas que se assemelham e tratem das mesmas temáticas, e formar o que Stanislavski (2012) denomina de unidades de ação.

Após escolher o recorte que configure uma unidade de ação, o ator precisaria conhecer o objetivo da sua personagem naquela unidade. Kusnet afirma ser importante que o ator se mantenha focado no objetivo da personagem, pois, caso 
não consiga interessar-se pelos problemas desta, "há pouca possibilidade de sucesso em seu trabalho. Já que é ele próprio que estabelece e da forma aos objetivos" (Kusnet, 1985, p.31). Na prática, isso significaria identificar, dentro das condições da existência ficcional proposta pela dramaturgia, as motivações e justificativas para a ações da personagem, ou, como Stanislavski denomina, os objetivos desta dentro das circunstâncias dadas (Stanislavski, 2012).

Kusnet aborda a circunstâncias dadas da seguinte forma: "para nós, atores, esse termo significa a verdade, a realidade da vida do personagem nas situações que o autor da obra dramática nos propõe" (Kusnet, 1985, p. 35). De forma que, saber em relação a cena estudada onde, quando, por que, o quê e com quem, é apontado como o caminho para identificá-la (Stanislavski, 2012). Para Kusnet, o bom conhecimento das circunstâncias dadas auxiliaria o ator a descobrir o objetivo da personagem em cada cena.

Portanto, convenhamos que em teatro não possamos admitir que a ação cênica seja desprovida de objetivos. Como na vida real, a atividade estimula a atividade dos seres humanos dentro de uma determinada situação, assim também em teatro o objetivo estimula a imaginação do ator e o induz a agir dentro das circunstâncias da obra dramática (Kusnet, 1985, p.29).

Kusnet ainda cita ainda a técnica do e se..., para que o ator reconheça e se coloque no lugar da personagem com o intuito de descobrir as motivações que a levam a agir de determinada maneira em cena. Nesse aspecto, ressalta que o ator precisaria necessariamente assumir as circunstâncias dadas e os objetivos da personagem, para que as motivações do ator não se confundam com as motivações desta. A união das unidades de ação e dos objetivos deveriam formar uma linha coerente de ação, resultando em ações tanto mentais quanto físicas que possuam lógica, como se cada ação fosse uma espécie de resposta ao que ocorreu em ação anterior. Por conta disso, seria importante o ator sempre revisar e criar justificavas de tudo que ocorre na mente da personagem, para que a sua vida interior e ações possuam coerência e realismo para quem assiste.

Realizados os passos anteriores, o ator poderia então encontrar a fé cênica, ou seja, a crença genuína na verdade teatral. Kusnet entende a verdade teatral 
como "a ação dentro da lógica da situação e dos objetivos da personagem" (Kusnet, 1985. p. 15). E para designar aquilo que sintetizaria "o resultado do uso de todos os elementos do Método, que o intérprete do papel tivesse empregado no seu trabalho com o texto” (Kusnet, 1985, p.71), apresenta a expressão monólogo interior. O monólogo interior seria a junção lógica dos pensamentos de uma personagem, que se configuraria dentro de uma corrente coerente, estabelecendo o que ocorre antes, durante e depois da ação descrita no texto dramático. Segundo Kusnet, esse elemento do método só poderia ser realizado após uma boa apropriação da fé cênica, do reconhecimento das circunstâncias dadas e consolidado por meio do improviso.

O verdadeiro Monólogo Interior só pode ser estabelecido depois do uso dos elementos necessários, culminados pela "fé cênica" e só pode ser criado espontaneamente, isto é, por meio de uma improvisação da ação do personagem dentro das "Circunstâncias Propostas" (Kusnet, 1985. p.71).

A Análise Ativa propriamente dita, portanto, ocorreria somente por meio da execução da improvisação, mas, para que possa ser feita adequadamente, seria preciso que os intérpretes possuíssem antes um conhecimento mínimo sobre a peça, a ponto de conseguirem contar os ocorridos da obra dramática. Nesse aspecto, a espontaneidade, a criatividade e os estudos sobre a dramaturgia são apontados como elementos primordiais.

Stanislavski não se cansava de repetir que o método de "Análise Ativa" permite ao ator incluir no processo de análise não somente o seu cérebro, como também o seu corpo. Assim o ator penetra fisicamente no âmago da ação dos choques e dos conflitos em que o personagem toma parte (Kusnet, 1985, p.102).

Para Kusnet, a Análise Ativa enquanto prática se pautaria em uma série de improvisações em cima das circunstâncias dadas, em que o ator age e reage de acordo com os objetivos da sua personagem. A expectativa é que, a partir das improvisações, o ator obtenha maiores informações e materiais a respeito da vida interior da personagem, ao mesmo tempo em que busca uma atuação livre de clichês, aliando, conforme as premissas de Stanislavski, aspectos psíquicos e 
físicos durante o processo de estudo e composição.

A improvisação de uma cena representa execução de uma série de ações físicas cabíveis dentro das "circunstâncias propostas" que já sabemos, envolve automaticamente a ação interior do ator. A permanente interdependência desses dois fatores foi colocada por Stanislavski como alicerce para o seu "método de ações físicas" Mais tarde esse método, com apenas algumas alterações de ordem técnica, transformou-se no que conhecemos hoje como "Análise Ativa" (Kusnet, 1985, p.101).

A escolha da Análise Ativa como a principal ferramenta metodológica de investigação cênica no processo criativo de Complexo de Ofélia se deu em virtude das possibilidades abertas pela dinâmica que ela instaura, sobretudo, o componente improvisacional. Entretanto, a Análise Ativa não foi elaborada para ser aplicada em um processo criativo remoto, e pressupõe originalmente as condições básicas de um ensaio de teatro presencial, com o envolvimento do corpo do ator na ação e a presença em um mesmo espaço físico dos atores e do diretor, o que coloca aos artistas envolvidos a seguinte questão: que espécies de adaptações seriam necessárias para que a Análise Ativa se configure como uma ferramenta passível de ser aplicada em um processo criativo remoto. Tal dificuldade será o assunto do próximo tópico.

\section{Análise Ativa e o RPG: relações possíveis na composição de uma abordagem metodológica de criação em teatro virtual}

O Role-Playing Game (RPG) é um jogo que se tornou popular nas décadas de 1980 e 1990, e tem como característica a possibilidade de criar RPGs de praticamente qualquer tema, pois o que define o jogo são suas regras, e não o universo temático abordado. Os principais elementos do RPG são: o mestre, os dados, os livros de regras, as aventuras, os mapas e as miniaturas. A dinâmica geral do RPG funciona da seguinte forma: o mestre apresenta oralmente uma narrativa e expõe situações para que as personagens, controladas pelos jogadores, resolvam. As personagens, conforme as habilidades individuais determinadas no livro do jogador, apresentam ideias para solucionar os problemas apresentados. Então, o jogador joga um dado - geralmente de 20 faces - que determina o 
fracasso ou sucesso da empreitada: quanto maior ou menor o número obtido, maior ou menor será a chance de sucesso ou fracasso. As cenas de jogos de RPG's de mesa ocorrem no imaginário dos jogadores, sendo interpelado pelas ações do mestre e pela dinâmica dos demais elementos do jogo.

A pesquisa optou pela adaptação das regras do jogo Doungeons and Dragons versão 3.5 (D\&D) em diálogo com o material dramatúrgico elaborado previamente para a peça, posto que o D\&D “é um jogo de fantasia que utiliza a imaginação. Em parte, ele envolve a interpretação, em outra ele é uma brincadeira narrativa, mas também abrange a interação social, aspectos dos jogos de estratégia" (Cook, 2004, p. 4). O D\&D 3.5 possui alguns livros de regras que norteiam como os jogadores e o mestre podem jogar, enquanto os dados determinam o sucesso ou fracasso das ações das personagens, além de servirem para definir testes de resistência a magia, danos e porcentagens utilizadas em batalhas. O mestre, por sua vez, deverá controlar os monstros e inimigos, descrever o ambiente, julgar as ações com base nos livros de regras e criar as aventuras.

O ponto de aproximação entre o teatro e o RPG são as regras e o seu formato: um grupo de pessoas que interpretam suas personagens por meio da narrativa oral improvisada. Com o objetivo de efetuar uma adequada transição do espaço de ensaio/palco presencial para o ambiente online, o processo criativo fez uso de elementos do jogo de RPG de mesa nos ensaios e na própria concepção das cenas. Como parte das adaptações necessárias, optou-se por não utilizar os livros de regras e dados, sendo o livro de regras substituído pelo texto dramatúrgico escrito a partir das personagens shakespearianas. Como não se criava um jogo sobre uma peça teatral, e sim uma peça teatral que possui elementos provindos do jogo, focou-se no uso apenas dos seguintes fatores do D\&D: o mestre, as aventuras, os mapas e miniaturas e a interpretação.

Dentro do contexto cênico da peça Complexo de Ofélia, a figura do mestre no RPG alcançou o posto de narrador, com a responsabilidade de guiar o público pelo imaginário coletivo ao longo da cena. Nas palavras de Lígia Borges Matias ${ }^{7}$ (2010, p. 77), no teatro narrativo: 
Cria-se uma relação na qual algo é dito pelo narrador que está em cena, imaginado em conjunto pela audiência e levado adiante por meio da história. Essa só é possível porque os assuntos abordados pertencem igualmente ao imaginário de todos os envolvidos.

Outro elemento adaptado são as aventuras. Dentro do jogo de mesa, aventuras são situações diversas e que podem servir à qualquer temática, constituindo uma história a ser vivida pelas personagens dos jogadores. As aventuras são preparadas pelo mestre, que guia as personagens dos jogadores por meio da narrativa oral. Não há regras quanto à temática de uma aventura, o único limitante à expansão da aventura é a imaginação de quem participa, pois "tudo é possível num jogo de Dungeons \& Dragons e o seu personagem pode fazer qualquer coisa que você imaginar" (Cook, 2004, p 4). A flexibilidade do RPG, que permite inúmeras possibilidades narrativas, é a principal característica em comum entre o jogo e a Análise Ativa, posto que o método stanislaviskiano também se pauta em uma estrutura que fornece abertura para diferentes abordagens e perspectivas criativas:

A eficácia do método [da Análise Ativa] e sua flexibilidade têm possibilitado o desvelamento da estrutura da ação em diferentes materiais textuais, respeitando o significado mais profundo do texto, possibilitando assim, uma criação original a partir da individualidade do diretor e do ator (D’Agostini, 2007, p.22-23).

Segundo Matteo Bonfitto (2011, p.57) “a noção de dramaturgia não está relacionada somente com a escritura de textos dramáticos, mas com a articulação dos diversos elementos que compõem a cena", e na medida em que o RPG mobiliza variados elementos para compor as cenas narrativas ao longo do jogo, é possível fazer uma relação entre as aventuras do D\&D com as dramaturgias do teatro. O texto dramatúrgico composto para o processo criativo de Complexo de Ofélia propunha uma narrativa de base envolvendo personagens femininas shakespearianos - Helena, Ofélia, Lady Macbeth e Julieta - dentro de uma única história. Possuindo a função de um disparador, e não um formato definitivo, o texto sofreu alterações durante o processo criativo a partir da colaboração das atrizes por meio de improvisações. 
Dentro do jogo de RPG, os jogadores são instigados a interpretarem suas personagens de acordo com as características que escolhem para si e as descritas nos livros de regras. A atuação ocorre de modo narrativo e improvisado, sobretudo de forma oral, mas cabendo variados níveis de interação corporal. Esse elemento improvisacional presente na interpretação do jogo de RPG consistiu no principal ponto de aproximação com a dinâmica da Análise Ativa, na medida em que o jogo apresenta um fator de imaginação e conhecimento do universo em que se passa (circunstâncias dadas), se aproximando das etapas do método que é conhecido como estudo de mesa (divisão de unidades de ação) e, por fim, o estudo do texto em ação (improviso).

Assim como no teatro stanislavskiano, no RPG os objetivos do personagem permeiam suas ações. Existe o superobjetivo e os objetivos menores que são construídos no decorrer do jogo e farão parte da evolução do personagem. No jogo os objetivos e o super-objetivo são chamados de quests. Existem a quest principal (superobjetivo) e as quests secundárias (objetivos que podem ou não interferir no superobjetivo). O personagem está sempre avaliando a situação diante do objetivo para então definir uma ação. Essa ação está sujeita às emoções do personagem e que não estão sujeitas a sua vontade, mas à do jogador - no caso do teatro à do dramaturgo, autor, diretor ou ator (Bragança, 2017, p.12).

Lissa Aryadne Santos Bragança ${ }^{8}$ ainda defende e exemplifica o uso de RPG em processos pedagógicos em teatro:

No ensino de teatro, por exemplo, podemos criar um jogo baseado em obras de Shakespeare. Por exemplo, a comédia "Sonhos de uma noite de verão" poderia ser o cenário onde os jogadores contariam a história narrada podendo ou não interpretar os personagens principais da obra (Bragança, 2017, p.11).

As miniaturas e mapas são elementos visuais do RPG que auxiliam a visualização e imaginação dos jogadores. Os mapas representam os locais em que a aventura está se passando, e as miniaturas as respectivas personagens. Com o desenvolvimento tecnológico, esses elementos passaram a ser não somente físicos, mas também programados em computador, o que culminou em versões

${ }^{8}$ Lissa Aryadne Santos Bragança é graduada em Artes Cênicas pela UnB; seu trabalho de conclusão de curso sobre versa sobre o uso do RPG no ensino de Teatro. 
online do jogo. A proposta cênica de Complexo de Ofélia utilizou esses elementos em sua versão digital, através dos programas MapTool e TolkenTool, para criar mapa e miniaturas personalizados, como forma de investigar a composição de ambientação e cenografias digitais que substituiriam os tradicionais aspectos cenográficos do teatro presencial. A estética de Complexo de Ofélia, nasceu, portanto, por meio das estruturas estabelecidas pelos elementos descritos acima, cuja abordagem final culmina em uma espécie de releitura do método da Análise Ativa de Stanislavski, resultante da interação com elementos do jogo do RPG.

\section{O processo criativo de Complexo de Ofélia}

Os primeiros ensaios da peça foram dedicados ao que seria o equivalente a um estudo de mesa, porém, adaptado ao modo remoto através do uso da plataforma Discord, e foram pautados na leitura e análise das obras originais de Shakespeare das quais saíram as personagens selecionadas para a dramaturgia. Em sequência, realizou-se a leitura do texto composto especificamente para o processo de criação, abrindo para que as atrizes pudessem debater e fazer proposições. Somente a partir desse ponto é que iniciou os procedimentos com base na Análise Ativa, momento em que se procurou dividir o texto dramático em unidades de ação, solicitando que as atrizes identificassem o objetivo de cada personagem nas cenas trabalhadas. As atrizes precisavam descobrir também, em cada uma das unidades, o que a sua personagem desejava e o que não desejava em cada cena (vontade e contra-vontade), e quais seriam as circunstâncias que as rodeavam, estabelecendo, para isso, o que havia ocorrido momentos antes da ação descrita no texto acontecer. Para a construção do mapa de ações passadas das personagens, nos casos em que tais informações não estivessem presentes na dramaturgia, era preciso que as atrizes completassem a narrativa com a imaginação, criando, destarte, uma linha lógica das ações do início ao término da peça.

O primeiro contato das atrizes com o RPG se deu por meio de sessões tradicionais do jogo, objetivando proporcionar o conhecimento da dinâmica e a experimentação de seus elementos. Após a etapa de familiarização com o RPG, a 
inserção dos elementos no universo temático da peça se deu principalmente por meio do elemento da narrativa, do mapa e das miniaturas, que buscavam adaptar o que deveria se passar no espaço do palco para o espaço cênico virtual. Durante os ensaios, utilizou-se um mapa feito no MapTool, aplicativo utilizado para confecção de mapas para RPG's, que permite ser atualizado ao vivo com miniaturas de personagens. Esse mapa era a representação visual do local em que as personagens estariam em cada momento da peça, o que auxiliava as atrizes e, futuramente, o público - a compreenderem a ambientação da narrativa e com quem e com o quê as personagens interagiriam, ajudando no estímulo imaginativo na função de um suporte visual. Além disso, com fins de preparação das atrizes para o momento da improvisação, executou-se jogos teatrais e jogos dramáticos adaptados para o formato remoto. As atrizes ressaltaram que a prática dos jogos antes das improvisações da Análise Ativa auxiliava na concentração, no foco e no processo de criação de suas personagens. A título de exemplo, um dos exercícios propostos consistia em uma entrevista com as personagens da peça, e tinha como objetivo servir como mecanismo de descobertas acerca de seus sentimentos, reflexões e motivações. As atrizes relatam que o exercício auxiliou alcançar maior naturalidade na atuação improvisada.

A organização da prática improvisacional organizou-se da seguinte forma: as atrizes improvisavam a partir do material dramatúrgico de base, sobretudo de forma oral, mas propondo gestos e ações corporais que dialogavam com a interação remota intermediada pelas câmeras e telas dos computadores. Para o improviso, deveriam considerar os objetivos de suas personagens e as circunstâncias dadas em cada unidade. Nas primeiras improvisações, as atrizes apresentaram bastante dificuldade, pois estavam muito presas ao texto dramático e o queriam reproduzir com perfeição, entretanto, com o tempo e a prática, tornaram-se mais abertas ao jogo da improvisação, superando as barreiras iniciais. Verificou-se que, conforme os ensaios remotos aconteciam, a criação do monólogo interior de cada personagem se aprofundava, e surgiam comentários como: "é impressionante como as personagens vão amadurecendo durante os diálogos" (informação verbal)9; ou "essa unidade é importante, pois dá um ritmo 
mais calmo ao andamento da peça" (informação verbal) ${ }^{10}$. O que se pode constatar é que, com o decorrer do tempo e o aumento da familiaridade para com a dinâmica dos ensaios remotos, as atrizes ficaram mais confortáveis com a abordagem metodológica adotada.

Uma dificuldade que surgiu durante os primeiros encontros foi em relação a fé cênica nas improvisações, o que ocasionava cenas com pouca lógica nas ações durante os diálogos. Por meio de apontamentos individuais por parte do diretor, tal como previsto na dinâmica original da Análise Ativa, as atrizes puderam refletir e aprimorar sua improvisação e, aos poucos, criar uma linha lógica para a interpretação, o que melhorou consideravelmente a qualidade das cenas. Além disso, para que as cenas alcançassem o ritmo desejado pelo diretor, era sugerido a criação de ações físicas que se encaixavam na narrativa proposta, surtindo efeito positivo na qualidade expressiva das representações.

Em relação a ambiência espacial do espetáculo, cada atriz criou a cenografia e caracterização que utilizariam por meio do seguinte procedimento: escolhiam uma temática a ser trabalhada, com base nas características de suas personagens, e buscavam, dentro de suas casas, elementos e objetos para compor a cenografia, o figurino e a iluminação. Como resultado, cada atriz criou a sua caracterização e espacialidade de forma distinta umas das outras, gerando uma pluralidade cenográfica dentro da mesma cena.

A análise do processo revela que os elementos advindos do RPG contribuíram de forma significativa para o processo de adaptação que envolvia a prática da Análise Ativa de forma remota. Os elementos narrativos do RPG conseguiram auxiliar no diálogo com os meios digitais e, desta forma, deram um suporte fundamental para as atrizes em suas interações. Além disso, o mapa, como elemento de espacialidade e ambientação, auxiliou no que seria a transposição para o ambiente virtual dos elementos componentes da poética espacial da cena e, juntamente com o mestre-narrador (fusão das funções de mestre de RPG e narrador do espetáculo), facilitou o entendimento das circunstâncias da 
dramaturgia, tanto por parte das atrizes nos ensaios, quanto por parte do público na apresentação.

O espetáculo foi gravado ocorrendo de modo ininterrupto, como realmente aconteceria em um evento teatral presencial. Novos territórios de exploração criativa foram sendo descobertos ao longo dos ensaios, como formas de utilização da câmera e possíveis interações com ela, abrindo possibilidades distintas para a relação entre atrizes e público. Conclui-se, portanto, que apesar de todas as dificuldades e das limitações evidentes que um processo de criação teatral em modo remoto adquire, o diálogo proposto entre a Análise Ativa e o RPG revelou ser um caminho metodológico possível para lidar com as necessidades específicas de processos criativos e pedagógicos de teatro em ambiente virtual. Contudo, é imprescindível uma reflexão mais apurada dos limites e contornos desse modo de proceder, assim como desse modo de ver e fazer teatro.

\section{Afinal, teatro virtual é teatro?}

O teatro virtual pode ser entendido como teatro? Imprescindível retornar a essa pergunta após explanar os passos de criação da peça Complexo de Ofélia. A resposta dada pelo processo em questão compreende que sim, porém, ressalta: a experiência do teatro virtual não substitui e nem pode ser equiparada à experiência do teatro presencial, posto que tem impactos distintos na sensorialidade do espectador, como também nas formas de acontecimentos dos ensaios. O que o processo de criação de Complexo de Ofélia revela é que a modalidade entendida como teatro virtual pode agregar outros sentidos na forma de se pensar o que é teatro na contemporaneidade, contudo, os seus resultados artísticos se consolidam de forma diferente aos do teatro presencial.

Jorge Dubatti é categórico em sua posição quanto a necessidade do convívio presencial no que se define chamar por teatro, posto que, em sua visão, não poderia faltar no acontecimento teatral a "[...] reunião dos corpos viventes produzindo poiésis em convívio, onde haja geração corporal de poiésis e expectação" (Dubatti, 2014, p. 254). Contrasta, portanto, a noção de acontecimento convivial - encontro de corpo presente sem intermediações tecnológicas - com o 
tecnovívio, "cultura vivente desterritorializada pela intermediação tecnológica" (Dubatti, 2012, p. 22). O posicionamento de Dubatti se assenta na concepção de convívio como um "paradigma das relações humanas" (Dubatti, 2012, p. 22), pois estaria ligado a um vínculo convivial ancestral. Todavia, uma reflexão: restringir a experiência desse vínculo à presencialidade física ainda faria sentido em uma contemporaneidade tão atravessada por convivialidades instauradas em espaços digitais, sobretudo em tempos - pandêmicos - que impõem a convivência virtual como uma das poucas possibilidades de experienciar a companhia de outros?

Ainda que a concepção proposta por Dubatti não localize o entendimento de teatro virtual na noção de convívio, o autor explana de forma muito consistente as diferenças de experiências instauradas quando a interação humana ocorre por meio da presença física dos corpos dos artistas e dos expectadores, e quando o corpo do ator está ausente e é substituído por uma estrutura sígnica (Dubatti, 2012). A organização da experiência de uma situação técnovial é determinada pelo formato tecnológico, logo, a experiência do teatro virtual não pode ser simetrizada à experiência do teatro presencial, pois "cada tecnologia determina modificações nas condições do viver junto" (Dubatti, 2012, p.23).

Desirée Pessoa (2020, s/p.) defende que "o futuro do teatro é aquele que compreende real e virtual, presença e potência, arte e tecnologia como dimensões que podem andar paralelamente ou entrelaçadas", posto que a escolha final sempre estará a cargo da pessoa que cria. Ao encontro desse modo de ver, Marco Aurélio Pinotti Catalão (2016, p.94) afirma: "a partir do momento em que expandimos o alcance do termo 'teatro' para além de sua realização efêmera, singular e irreproduzível, obtemos uma perspectiva mais ampla sobre a criação cênica contemporânea". Tais perspectivas compreendem que esse modo de conceber teatro se pauta principalmente na presença e na potência do que é apresentado, deixando de lado a efemeridade e a presença física, colocando em pauta a discussão sobre as margens do que pode ou não ser considerado teatro. Movimento complexo e arriscado, pois, apesar da divisão em momentos históricos e formas de abordagens que marca os debates teóricos no campo artístico, "é fato que estamos diante de uma zona de contaminação que transforma suas fronteiras em zonas de indefinição, levando a formas híbridas de criação” (Monteiro, 2016, p. 
95). Mas, se for preciso demarcar algumas linhas divisórias norteadoras, inspiramonos, então, em Silmara Lídia Moraes Arcoverde (2008. p. 603): “a participação no teatro é a sua essência”, entendendo teatro, portanto, como a efetiva participação no ato por parte do público, dos atores, dos diretores e dos técnicos enquanto o elemento configurador do acontecimento teatral, ainda que por meio de uma presença que transcende o espaço físico e se concretize na consciência através dos recursos tecnológicos. A presença no teatro virtual se dá, portanto, como consciência coletiva da participação de todos os envolvidos.

Outro questionamento comum é se o teatro virtual não seria apenas mais uma forma de produto audiovisual. Nesse sentido, Ivam Cabral (Santana, 2020, online) acredita que "não se trata de uma experiência audiovisual. Estamos presentes. A gente não tem uma itha de edição ou equipamentos mirabolantes. É o velho jogo do faz de conta”. Contudo, o audiovisual e o teatro virtual se assemelham em diversos fatores, sejam eles técnicos ou midiáticos, o que tornaria complexo traçar aqui um paralelo entre as suas fronteiras, posto que, uma vez que as artes da cena possuem diversas linguagens diferentes - a performance, o teatro-imagem, o teatro épico, entre outras - o audiovisual também contém suas próprias particularidades. E por conta dessas particularidades, haverá linguagens dessa arte que se aproximarão do que está sendo produzido e entendido como teatro virtual, e outras que se distanciarão completamente. Por ora, fechamos com a concepção de Daniele Small acerca do assunto: "Temos de ver caso a caso, porque às vezes é sim e não. Na arte contemporânea - e o teatro faz parte disso, ele não está separado do que o mundo faz -, a experiência do público é que vai 'onde aquilo se encaixa" (Santana, 2020, online).

Dessa maneira, é possível concluir que a presença física em um único ambiente não é imprescindível para o acontecimento teatral - importante característica em uma contemporaneidade cada vez mais globalizada e tecnológica. Porém, a experiência do teatro virtual não pode ser simetrizada à experiência do teatro presencial. Apesar disso, o teatro virtual tem potência para ser mais do que apenas uma alternativa emergencial de produção cênica em contexto pandêmico, e sim, uma outra possibilidade de abordagem dentro do grande rol de experiências que se entende por teatro contemporâneo. 


\section{Referências}

ARCOVERDE, Silmara Lídia Moraes. A importância do teatro na formação da criança. In: Anais do educere - congresso nacional de educação, 3., 2008, Curitiba, p. 600-609, 2009.

BRAGANÇA, Lissa Aryadne Santos. O uso do RPG no ensino de teatro: um relato de experiência. 2017. Artigo (Trabalho de Conclusão de Curso) - Curso de Licenciatura em Artes Cênicas - Universidade de Brasília, Brasília, 2017.

BONFITTO, Matteo. Tecendo os sentidos: a dramaturgia como textura. Pitágoras, Campinas, v. 1, n. 500, p. 56-61, 2011.

CATALÃO, Marco Aurélio Pinotti. Teatro virtual: teoria e prática. ARJ - Art Research Journal / Revista de Pesquisa em Artes, [S.I.], v. 3, n. 1, p. 92-106, 2016.

DUBATTI, Jorge. Teatro, convívio e tecnovívio. In: CARREIRA, André Luiz Antunes Netto; BIÃO, Armindo Jorge de Carvalho; TORRES NETO, Walter Lima (org.). Da Cena Contemporânea. Porto Alegre: ABRACE - Associação Brasileira de Pesquisa e PósGraduação em Artes Cênicas, 2012.

CARNICKE, S. M Sharon Marie; CARVALHO, Felipe Rodrigues. Stanislávski: sem censura nem cortes. Urdimento - Revista de Estudos em Artes Cênicas, Florianópolis, v. 1, n. 40, p. 1-20, 2021.

COOK, Monte. Dungeons and Dragons: Livro do jogador. São Paulo: Devir Livraria, 2004.

D’AGOSTINI, Nair. O método de análise ativa de K. Stanislávski como base para a leitura do texto e da criação do espetáculo pelo diretor e ator. [S.I.]. Tese (Doutorado em letras) - Universidade de São Paulo, São Paulo, 2007.

FRITSCH, Marcus. Metamorfoses teóricas e práticas do Étude, na perspectiva de Anatóli Vassíliev. O Percevejo Online, Rio de Janeiro, v. 7, n. 2, p. 104-116, 2015. Disponível em:

http://www.seer.unirio.br/index.php/opercevejoonline/article/view/5627/5143

Acesso em: 23 mar. 2021.

KUSNET, Eugênio. Ator e método. Rio de Janeiro: Instituto Nacional de Artes Cênicas, 1985.

MATIAS, Lígia Borges. Investigação acerca do uso da narrativa no teatro contemporâneo. 2010. Tese (Doutorado em Artes Cênicas) - Universidade Estadual Paulista, São Paulo, 2010. 
MONTEIRO, G. L. G. A Cena Expandida: alguns pressupostos para o teatro do século XXI. ARJ - Art Research Journal / Revista de Pesquisa em Artes, v. 3, n. 1, p. 37-49, 2016.

MOSCHKOVICH, Diego Fernandes Garcia. O último Stanislávski em ação: tradução e análise das experiências do Estúdio de Ópera e Arte Dramática (1935 - 1938). 2019. Tese (Doutorado em Artes Cênicas) - Universidade de São Paulo, São Paulo, 2019a.

MOSCHKOVICH, D. O último estúdio de Stanislávski: uma abordagem histórica. Sala Preta, São Paulo, v. 19, n. 1, p. 229-259, $2019 b$.

PESSOA, D. O teatro do futuro é virtual, aposta pesquisadora e encenadora. In: GZH Espetáculos. 13/08/2020. Disponível em:

https://gauchazh.clicrbs.com.br/cultura-e-lazer/espetaculos/noticia/2020/08/oteatro-do-futuro-e-virtual-aposta-pesquisadora-e-encenadorackdt1voli003i013g7xgxdt70.html. Acesso em: 25 maio 2021.

ROMAGNOLLI, Luciana Eastwood; MUNIZ, Mariana de Lima. Teatro como acontecimento convival: uma entrevista com Jorge Dubatti. Urdimento - Revista de Estudos em Artes Cênicas, Florianópolis, v. 2, n. 23, p. 251 - 261, 2014.

SANTANA, Willian Nunes. É teatro, não é teatro: no palco físico ou digital, a arte do teatro urge. In: Terras de Cabral - O Blog do Ivan. 31 de julho 2020. Disponível em: https://terrasdecabral.com.br/no-palco-fisico-ou-digital-a-arte-do-teatro-urge/ .Acesso em: 25 maio 2021.

STANISLAVSKI, Constantin. A preparação do ator. Rio de Janeiro: Civilização Brasileira, 2012.

TIBURI, Márcia. Ofélia morta: do discurso à imagem. Revista Estudos Feministas, [S.L.], v. 18, n. 2, p. 301-318, 2010. FapUNIFESP (SciELO). http://dx.doi.org/10.1590/s0104-026×2010000200002 . 